\title{
Comorbidities of sleep disorders in childhood and adolescence: focus on migraine
}

This article was published in the following Dove Press journal:

Nature and Science of Sleep

10 June 2013

Number of times this article has been viewed

\author{
Claudia Dosi ${ }^{1}$ \\ Assia Riccioni' \\ Martina della Corte \\ Luana Novelli' \\ Raffaele Ferri² \\ Oliviero Bruni' \\ 'Department of Social and \\ Developmental Psychology, Sapienza \\ University, Rome, Italy; ${ }^{2}$ Sleep \\ Research Centre, Oasi Institute for \\ Research on Mental Retardation and \\ Brain Aging (IRCCS), Troina, Italy
}

\begin{abstract}
The correlation and/or comorbidity between sleep disorders and headache has been reported in numerous studies, but the exact nature of the association between headache, disordered sleep, and underlying mechanisms remains poorly understood. The bidirectional association between sleep and headache is mediated by a temporal link (headache occurs during sleep, after sleep, and in relationship with sleep stages), by a quantitative relationship (excess, lack, bad quality, short duration of sleep may trigger headache), and by a reciprocal connection (headache may cause sleep disruption and may be associated with several sleep disturbances). This association is most evident for primary headache disorders, especially in childhood. A congenital alteration of neurotransmitter pathways (serotoninergic and dopaminergic) might predispose individuals to both disorders, presenting as sleep-wake rhythm disorder in infancy or as headache disorder later in childhood, as result of this neurotransmitter imbalance. Clinicians should be aware that a complete clinical evaluation of childhood headache includes a careful sleep history, taking into account that the treatment of sleep disturbances could lead to an improvement of headache symptoms and vice versa.
\end{abstract}

Keywords: sleep, headache, migraine, childhood, adolescence

\section{Introduction}

Different scientific reports in the literature have suggested the existence of a correlation and/or comorbidity between sleep disorders and headache, related to common pathophysiological substrates.

An old report of a child with sleep apnea at the end of the nineteenth century by $\mathrm{Hill}^{1}$ raised the problem of a possible association between headache and sleepdisordered breathing with a relevant passage stating that: "The stupid-looking lazy child who frequently suffers from headache at school, breathes through his mouth instead of his nose, snores and is restless at night, and wakes up with a dry mouth in the morning, is well worthy of the solicitous attention of the school medical officer." However, a clear pathogenetic explanation of this association was not attempted, and presumably it was an example of the "Headache attributed to disorder of homeostasis and linked to the hypercapnia and hypercarbia," coded as ICHD 10, ICD10 G44.882, in the International Classification of Headache Disorders (ICHD) 2004. ${ }^{2}$ Since then, several aspects of the comorbidity between sleep and headache have been investigated and confirmed by the medical literature. ${ }^{3-5}$

However, the exact nature and magnitude of the association between headache, disordered sleep, and the underlying mechanisms remain poorly understood. ${ }^{6}$ It is known that sleep is related to the occurrence of some headache syndromes, while 
headache may cause various degrees of sleep disruption and seems to be associated with several sleep disturbances, either in adults or children. ${ }^{7,8}$

Headache episodes are known to occur during sleep, after sleep, and in relationship with various sleep stages, and on the other hand an excess or lack of sleep or bad quality or inadequate duration of sleep can trigger headache., ${ }^{9,10}$

Nocturnal migraine attacks are typical effects of sleep disruption, and conversely primary headaches may emerge during nocturnal sleep time, causing sleep disruption. ${ }^{3,11}$

\section{Incidence and prevalence of sleep disorders in headache and migraine}

Both sleep disturbances and headache disorders are widespread health problems during childhood: the aggregate weighted rate of definite migraine in children is $10.1 \%$, while approximately $25 \%$ of children have experienced at least one type of sleep problem. ${ }^{12,13}$

Even though several studies have demonstrated a high prevalence of sleep disorders in subjects with headache, they cannot be seen as a comorbid or causative factor for headache. ${ }^{14}$ While patients complain about their sleep disorders, these manifestations are usually considered as "common insomnia" of psychological origin and tend to be considered as not relevant by physicians. ${ }^{15,16}$

In children, the perception of disturbed sleep is missed or underestimated, and it is generally easier for a child to refer to a headache than poor sleep quality. Therefore, the symptom "headache" in children has to be evaluated from different points of view, including an accurate evaluation of sleep behaviors and disturbances.

In general, the relationship between headache and sleep disorders might be mediated by pain: a large community study on 622 children and adolescents with pain $(60 \%$ with headache) reported that the most common complaints caused by pain were sleep disturbances $(53.6 \%)$, followed by the inability to pursue hobbies (53.3\%), eating problems (51.1\%), and absence from school (48.8\%). Moreover, one of the most frequent self-perceived subjective triggers of pain was the lack of sleep. ${ }^{17}$

Children who suffer from headache have usually a high rate of sleep difficulties, including insufficient sleep, cosleeping, difficulties falling asleep, anxiety related to sleep, restless sleep, night waking, nightmares, and fatigue during the day. ${ }^{5,7}$ Different surveys in large pediatric populations have confirmed the strong association between headache and different sleep disorders, such as parasomnias, insomnia, sleep-breathing disorders, and daytime sleepiness. ${ }^{18-20}$
The first survey on a pediatric population confirmed the strong association between headache and different sleep disorders. ${ }^{18}$ It was a questionnaire-based study involving 283 headache sufferers (144 male, 139 female) aged 5.0-14.3 years: 164 with migraine $(\mathrm{M})$ headache (141 without aura and 23 with aura) and 119 with tension-type (T) headache (84 episodic tension-type headache and 35 chronic tension-type headache), compared to an age-matched healthy control (C) group. Significant differences between headache and controls were found:

1. Sleep duration and sleep latency: children with migraine and tension-type headache presented shorter sleep duration (duration $<8$ hours in about $18 \%$ of children with headache vs $9.6 \%$ of controls) and a sleep latency $>30$ minutes in $13.4 \%$ vs $6.6 \%$.

2. Bedtime problems: children with headache showed a higher prevalence of difficulty to get asleep $(M=20.1 \%$, $\mathrm{T}=17.6 \%, \mathrm{C}=8.9 \%$ ) and of fears or anxiety when falling asleep $(\mathrm{M}=30.5 \%, \mathrm{~T}=22.7 \%, \mathrm{C}=8.2 \%)$.

3. Night awakenings: subjects with headache showed a more interrupted sleep, with more than two awakenings per night in about $13 \%$ of the headache group vs $6.83 \%$ of controls.

4. Parasomnias: sleep talking, bruxism, and reports of frightening dreams were the items in which children with migraine were significantly different from controls, while no differences were observed regarding the prevalence of sleepwalking, bed-wetting, or sleep terrors (Table 1). Analyzing the migraine subgroups, a higher frequency of sleepwalking was found in migraine with aura (13.04\%) vs migraine without aura (2.84\%) and vs controls (3.14\%).

5. Sleep-breathing disorders: sleep-breathing problems were more frequent in subjects with migraine vs controls, while tension-type headache failed to show differences (Table 2), ${ }^{6,7}$ confirming data already reported in children and in adults. ${ }^{21,22}$

6. Morning symptoms and daytime sleepiness: both groups of subjects with migraine (35.37\%) and tension-type headache $(30.25 \%)$ presented more restless sleep than controls (19.71\%); daytime sleepiness affected both headache groups in a higher percentage with respect to controls (12.20\% in M, $10.92 \%$ in $\mathrm{T}, 4.48 \%$ in $\mathrm{C}$ ), and represented a worsening factor for quality of life.

Although no significant differences were found between the migraine and headache groups, the subjects with migraine tended to have the most "disturbed sleep" with a greater prevalence of nocturnal symptoms, such as sleep-breathing disorders and some parasomnias. 
Table I Prevalence of parasomnias and sleep-breathing disorders (frequency more than once a week) (Bruni et al, 1997) ${ }^{18}$

\begin{tabular}{|c|c|c|c|c|}
\hline & Controls & Migraine & $\begin{array}{l}\text { Tension- } \\
\text { type }\end{array}$ & $\begin{array}{l}\text { Significant } \\
\text { differences } \\
\text { vs controls }\end{array}$ \\
\hline \multicolumn{5}{|l|}{ Parasomnias } \\
\hline Hypnic jerks & $5.0 \%$ & $16.5 \% * *$ & $14.3 \% * *$ & $\mathrm{M}$ and $\mathrm{T}$ \\
\hline $\begin{array}{l}\text { Rhythmic movements } \\
\text { while falling asleep }\end{array}$ & $2.7 \%$ & $6.1 \% *$ & $5.0 \%$ & M \\
\hline $\begin{array}{l}\text { Hypnagogic } \\
\text { hallucinations }\end{array}$ & $1.5 \%$ & $4.3 \% *$ & $4.2 \% *$ & $\mathrm{M}$ and $\mathrm{T}$ \\
\hline Sleepwalking & $3.1 \%$ & $4.3 \%$ & $4.2 \%$ & NS \\
\hline Sleep talking & $14.4 \%$ & $28.7 \% *$ & $19.3 \%$ & $M$ \\
\hline Bed-wetting & $2.3 \%$ & $3.7 \%$ & $3.4 \%$ & NS \\
\hline Bruxism & $7.4 \%$ & $12.2 \% *$ & $7.6 \%$ & $M$ \\
\hline Sleep terrors & $1.3 \%$ & $3.0 \%$ & $1.7 \%$ & NS \\
\hline Nightmares & $2.5 \%$ & $8.5 \% * *$ & $6.7 \% * *$ & $\mathrm{M}$ and $\mathrm{T}$ \\
\hline $\begin{array}{l}\text { Report of frightening } \\
\text { dream }\end{array}$ & $10.6 \%$ & $18.9 \% *$ & $12.6 \%$ & M \\
\hline \multicolumn{5}{|c|}{ Sleep-breathing disorders } \\
\hline $\begin{array}{l}\text { Sleep-breathing } \\
\text { difficulties }\end{array}$ & $6.8 \%$ & $16.5 \% * *$ & $10.1 \%$ & M \\
\hline Sleep apnea & $1.0 \%$ & $6.1 \% * *$ & $3.4 \%$ & $M$ \\
\hline Snoring & $14.7 \%$ & $21.9 \% *$ & $15.9 \%$ & M \\
\hline
\end{tabular}

Notes: ${ }^{\dagger}$ No differences were found between $M$ and $T ; * P<0.05$; $* * P<0.005$

Abbreviations: $M$, migraine; $T$, tension-type headache.

Twenty out of $283(7.77 \%)$ subjects presented recurrent nocturnal headache attacks and reported more sleep disorders than patients with diurnal attacks. The occurrence of nocturnal headache attacks deeply modifies the sleep pattern and affects the occurrence of night symptoms, confirming the involvement of common pathways in the pathogenesis of both conditions.

In the same study, subjects with migraine reported a higher prevalence of sleep disturbances in parents, sleep disturbances in infancy, and colics, as well as an elevated level of familiarity for headache, showing that a genetic link might be present between migraine and disturbed sleep and indicating that the common neurobiological substrate might act from the beginning of life and/or that a comorbidity exists between these two disorders. This hereditary connection was not sufficiently supported in subjects with tension-type headache.

After this pioneering study, other studies confirmed the strong association between headache and such sleep disorders as parasomnias, insomnia, snoring, sleep apnea, and daytime sleepiness, reporting a general prevalence of sleep disturbances in $25 \%-40 \%$ of children and adolescents with migraine. ${ }^{23,24}$

A subsequent study demonstrated a specific comorbidity between these two conditions, showing in a variable range sleep-time reduction (42\%), bruxism (29\%), and snoring
$(23 \%)$ in a group of 118 patients. ${ }^{19}$ Looking at the different migraine types, snoring, parasomnias, sweating during sleep, and daytime sleepiness were more common among children with migraine, compared with nonmigraine and no-headache groups, ${ }^{25}$ while schoolchildren with migraine without aura had a higher prevalence of sleep-disorder symptoms: disorders of initiating and maintaining sleep (37.11\% of migraine without aura vs $9.17 \%$ of controls), and disorders of arousal (59.32\% of migraine without aura vs $10.15 \%$ of controls). ${ }^{26}$

On the contrary, only one study failed to corroborate the higher prevalence of symptoms of sleep apnea, restlessness, and parasomnias reported in the previous studies, but confirmed the presence of excessive daytime sleepiness, narcolepsy, and insomnia in children with headaches. ${ }^{27-29}$

Carotenuto et al showed that migraine without aura is a sensitive risk factor for disorders of initiating and maintaining sleep and chronic tension-type headache for sleep-breathing disorders, but headache disorder is a cumulative risk factor for disorders of excessive somnolence. ${ }^{30}$

It has also been demonstrated that frequency and duration of migraine headaches predicted specific sleep disturbances, such as sleep anxiety, parasomnias, and bedtime resistance. Consequently, head pain might be the consequence of a subtle sleep disorder not diagnosed or of bad sleep habits. ${ }^{19}$

Pakalnis et $\mathrm{al}^{31}$ recently reported a significant association between sleep and emotional disorders and migraine severity, revealing that patients with chronic migraine had increased daytime sleepiness and dysthymia compared with teenagers with episodic migraine. Specifically, headache patients compared with controls had worse pediatric sleep questionnaire total score, more morning headaches, and more sleepiness. The child sleep habits questionnaire (CSHQ) revealed that the headache group had more daytime sleepiness, night awakenings, sleep-onset delay, parasomnias, and total questionnaire score compared with controls. The same authors also reported no association between serotonin levels and sleep abnormalities or emotional rating scales, while increased caffeine intake was related to sleep and depressive complaints.

According to Pakalnis et al, ${ }^{31}$ a recent study reported a significant association of primary headaches in children with anxiety and depression, as in adults, while no significant association was found with asthma and allergic disorders, convulsive episodes, sleep disorders, or increased body weight. ${ }^{32}$ 


\section{Comorbidity of early sleep problems and migraine}

Sleep problems during infancy can be good predictors for the development of headache. In particular, early onset sleep disorders have been found to be predictive of headache persistence from infancy to childhood: they were reported in $78 \%$ of children with enduring headache vs $25 \%$ of children showing headache remission. Further, early sleep disorders have been related to psychiatric comorbidity and involved in the endurance of headache in childhood and adolescence: an 8-year follow-up study found that the most frequent comorbid disorders at the onset of headache were sleep disorders (12\%) followed by anxiety (11\%); of the nine patients with sleep disorders as comorbid factor at the onset of headache, six had enduring headache and three were headache-free at follow-up. ${ }^{33}$

Colicky infants are considered to be candidates for sleep disorders, and some reports have shown a relationship also with migraine. ${ }^{34,35}$ It is known that infantile colic is a periodic behavior in infants and a common cause of crying and pain in childhood; these two symptoms, in some genetically predisposed infants, could represent a form of infantile migraine with age-specific expression. ${ }^{34}$ The prevalence of colics in children with migraine is higher than in the control population: Bruni et $\mathrm{al}^{18}$ reported a positive history of colic in $38.4 \%$ of subjects with migraine, which was significantly higher than controls $(26.9 \%)$ and subjects with tensive headache (25.2\%). This was further supported by another study showing an increased positive history of colic in children with migraine ( $52 \%$ vs $20 \%$ in controls). ${ }^{34}$ Katerji and Painter ${ }^{35}$ reported a case of a colicky infant with irritability, head-slapping with the hands, upper-eyelid retraction, and family history of migraine, suggesting that the excessive crying may have resulted from headache or represent an abdominal migraine variant. This finding has been corroborated by the improvement of colic after the start of migraine therapy (cyproheptadine).

In addition, hyper-reactivity syndrome during infancy (often associated with night awakenings and falling asleep difficulties) has been reported as a risk and predisposing factor for migraine..$^{36,37}$

It is therefore possible that the same pathogenetic mechanism underlying headache or migraine and sleep might play a role from early life, supporting the hypothesis of a common intrinsic origin.

\section{Circadian rhythms, sleep hygiene, and headache}

Headache has been described as being related to biological cycles, and there is evidence of a relationship of different headache syndromes with a variety of cyclic phenomena. Despite this, few studies have focused on the sleep-wake cycle and on the circadian aspects.

Migraine attacks show different periodicities: (1) a circadian periodicity of migraine attacks, with an overrepresentation during the waking hours (between 4 am and $9 \mathrm{am}$ ); (2) a menstrual periodicity, with a peak after the onset of menses; and (3) a weak seasonal periodicity, with a mild overrepresentation during summer. ${ }^{38}$

Several findings suggest a role of chronobiological factors in migraine, probably related to hypothalamic involvement. ${ }^{11,39}$ An indirect demonstration of the involvement of the circadian rhythm is the report of five patients with headache with associated delayed sleep-phase syndrome successfully treated with melatonin, which with its chronobiological action synchronizes the patients biological clock and their lifestyle. ${ }^{40}$ This finding supports the hypothesis that melatonin has a "sleep-hygiene effect," in accordance with the migraine improvement reported in children and adolescents after the application of sleep-hygiene guidelines. ${ }^{41}$

Melatonin is implicated in the pathogenesis of migraine, menstrual migraine, cyclic migraine, and chronic migraine, and it might also play a role in migraine comorbid disorders, in particular depression and insomnia. Melatonin is linked to the pathophysiology of headache, because of its anti-inflammatory effect, toxic free-radical scavenging, reduction of proinflammatory cytokine upregulation, nitric oxide synthase activity and dopamine-release inhibition, membrane stabilization, gamma-aminobutyric acid and opioid analgesia potentiation, glutamate neurotoxicity protection, neurovascular regulation, serotonin modulation, and the similarity of its chemical structure to that of indomethacin. ${ }^{42}$

Different studies have shown a decrease of melatonin levels in subjects with migraine and cluster headache and a positive response to the administration of melatonin in migraine, cluster, and hypnic headache..$^{42-57}$

Peres $^{42}$ studied the plasma melatonin nocturnal profile: lowered melatonin levels were observed in patients with insomnia compared with those without insomnia, and a phase delay in the melatonin peak was observed in patients vs controls, suggesting a chronobiological dysfunction in chronic migraineurs. 
Miano et $\mathrm{al}^{58}$ administered melatonin to 22 children with headache (13 had recurrent migraine without aura, one with aura, and eight had chronic tension-type headache), showing a decrease in the number of the headache attacks in 14 patients.

Melatonin in migraine might act also as a chronobiotic agent through a sleep-hygiene effect. Sleep hygiene has been defined as the conditions and practices that promote continuous and effective sleep: these include regularity of bedtime and rise time; conformity of time spent in bed to the time necessary for sustained and individually adequate sleep; restriction of beverages, foods, and compounds (which tend to disrupt sleep) before bedtime; and regular exercise, nutrition, and environmental factors so that they enhance rather than disturb restful sleep. In the first study published on sleep hygiene in adolescents with migraine, Bruni et $\mathrm{al}^{41}$ instructed 35 children and adolescents to follow directions to improve sleep hygiene, and patients showed a significant decrease in the mean duration and frequency of migraine attacks, while the severity of the attacks did not change.

The application of sleep-hygiene guidelines could represent an alternative approach to the treatment of migraine by correcting an inappropriate sleep behavior without recurring to pharmacological treatment.

The evaluation of the whole sleep cycle in children and adolescents has been carried out in actigraphic studies showing that sleep quality of children and adolescents with headache was poorer than that of controls. This study reported excessive daytime sleepiness, less time spent in quiet, motionless sleep, and waking significantly earlier in the morning. ${ }^{59}$ A previous study showed that during the interictal period, sleep parameters of children suffering from migraine did not differ from those of controls, but in the night preceding the migraine attack there was a decrease in nocturnal motor activity, indicating a decrease in cortical activation during the sleep period preceding migraine attacks. ${ }^{60}$

The preference for morning or evening activity patterns is believed to contribute to interindividual differences in the timing of circadian rhythms. The morning/evening preference might be considered as a continuum between two extremes: morning types (larks) and evening types (owls), but a consistent shift toward "eveningness" has been demonstrated during adolescent development. Children and adolescents with headache show a higher tendency to the eveningness circadian type. .1,62 $^{61}$

A previous study on the circadian timing of attacks in adult migraineurs showed a preferential timing for occurrence of migraine attacks during the night and early morning hours in a relevant percentage of patients. This study confirmed the hypothesis of an impairment of chronobiological rhythms occurring in migraine together with an alteration in melatonin secretion. ${ }^{63}$

\section{Sleep as a trigger and relieving factor for headache}

Different studies have reported that sleep problems were the most frequent causes of headache, followed by stress, family problems, and peers ${ }^{64-66}$ and the lack of sleep was identified as a trigger after certain weather conditions, illness, sports and physical activity, and anger. ${ }^{17}$

Bruni et $\mathrm{al}^{67}$ reported that in a nonclinical group of adolescents with headache, the most frequent triggering factor for headache referred to by adolescents was "a bad sleep" (32.2\%), followed by emotional distress (27.8\%). On the other hand, clinical studies have demonstrated that sleep, either spontaneous or induced by hypnotics, is efficacious in relieving headache or even terminating the attacks in headache sufferers. ${ }^{68,69}$ Falling asleep during attacks is significantly more frequent in patients younger than 8 years of age than in older children, and in these children there is a higher resolution of attacks with sleep. ${ }^{70}$

However, the power of sleep in terminating the attack is counterbalanced by its ability to precipitate the attack. Although sleep was more commonly referred to as a relieving factor for migraine $(70 \%)$, migraine attacks were also precipitated by sleep deprivation in $24 \%$ and by sleep excess in $6 \%$ of cases. ${ }^{71}$

It has been hypothesized that the depth of sleep might be responsible for the migraine attack, and the use of a technique named "sleep rationing" (consisting of the reduction of total sleep time and of relaxed sleep and practically leading to a reduction of rapid-eye-movement sleep), was successful in reducing both the intensity and severity of the migraine attacks. ${ }^{72}$

\section{Polysomnographic studies}

Only a few polysomnographic studies have analyzed sleep architecture in children with headache. Guidetti et $\mathrm{al}^{73}$ found that the main feature of sleep organization in children with migraine was represented by a high degree of sleep instability, as demonstrated by the increased number of stage shifts and movement time. The description by Paiva et $\mathrm{al}^{74}$ of changing diagnosis in several adults with headache after a polysomnographic study (periodic limb movements during sleep, fibromyalgia syndrome, and obstructive sleep apnea syndrome) raised the possibility of the presence of similar conditions in pediatric patients. 
These results are in agreement with a more recent study by Vendrame et $\mathrm{al},{ }^{75}$ who analyzed the polysomnographic features of 90 children manifesting headaches (including migraine headache, chronic migraine headache, tension headache, and nonspecific headache) and complaints of sleep problems. Children with migraine headache and chronic migraine headache were more frequently affected by sleepdisordered breathing than children with tension headache, indicating a strong clinical association between migraine and sleep-disordered breathing. In addition, sleep of children with severe migraine was characterized by a shorter duration of sleep time and higher sleep latency compared to children with milder migraine, while chronic migraine was associated with more disrupted sleep (ie, a higher arousal index than in children with migraine).

\section{Potential mechanisms underlying migraine and sleep disorders}

Sleep represents the only well-documented behavioral state related to the occurrence of some headache syndromes, and this correlation is linked to common pathophysiological substrates, especially hypothalamus, serotonin, and melatonin. ${ }^{11}$

The structure recognized to be a migraine generator is the trigeminal nucleus caudalis in the pons and midbrain, but the hypothalamus is also surely involved in the prodromal symptoms of migraine, such as yawning, hunger, cravings, fatigue, mood changes, and sensory and visual distortions, that are commonly considered as dopaminergic premonitory symptoms. ${ }^{76,77}$ The hypothalamus is connected with the limbic system, the pineal gland, the noradrenergic locus coeruleus, and the serotonergic dorsal raphe, which are anatomical structures involved in the control of the sleep-wake cycle as well as in the modulation of pain. ${ }^{78}$ The serotonergic system, in particular, might play an important role in the relationship between headache and sleep.

Also, dopamine is important in the pathogenesis of migraine: individuals susceptible to migraine appear to have genetic polymorphisms in the dopamine $\mathrm{D}_{2}$ gene, which increase responsiveness to dopamine, or defects in tyrosine hydroxylase, which inhibits dopamine metabolism, and an imbalance of the dopaminergic system is responsible for some premonitory symptoms of migraine, such as nausea, yawning, and dizziness. ${ }^{79,80}$ Finally, melatonin is a chronobiotic substance that has demonstrated therapeutic efficacy in some forms of migraine and headache. ${ }^{42,81,82}$

Based on this body of evidence, different studies have proposed a model of interaction between headache and sleep ${ }^{67,74,83}$ by combining clinical data and experimental evidence. The interrelationship between sleep and headache can be summarized as follows: ${ }^{11}$

(a) sleep could be a trigger factor for headache (excessive, reduced or disrupted, increased deep sleep can all determine the onset of the pain attack);

(b) sleep is often used by patient as relieving factor for headache;

(c) sleep disturbances can cause headache (ie morning headache in sleep apnea patients);

(d) bad sleep hygiene can worsen a pre-existing headache;

(e) sleep disorders are often present in headache patients (ie parasomnias, sleepwalking);

(f) headache attacks occurring during the night can be cause of sleep disturbance;

(g) headache can be related to specific sleep stages (REM or SWS);

(h) headache occur mostly during sleep or just after sleep;

(i) the association between headache and sleep is mediated by the same neurotransmitters (serotonin/dopamine).

The hypothesized structural alteration of serotoninergic and dopaminergic pathways affecting migraine and sleep might be at play from the early period of life, leading to disorders of the sleep-wake rhythm in infancy that tend to persist during childhood and adolescence, and to the development of a comorbid headache disorder as result of this neurotransmitter imbalance..$^{70,84,85}$

From the anatomical point of view, the intrinsic mechanism that leads to headache relief is still unknown and understudied. It is known that the processing of pain interacts with other vegetative functions, such as sleep, arousal, and sympathetic, parasympathetic, and neuroendocrinological functions.

As already reported, the hypothalamus has a crucial role in both headache and sleep disorders, and is strictly correlated with brain areas involved in the pathogenesis of migraine. The hypothalamus is closely connected with the limbic system, the retinohypothalamic tract, and brain-stem aminergic nuclei (including those of the dorsal raphe and the locus coeruleus). This anatomical framework can explain the autonomic symptoms that are the specific presentation of the migraine syndrome. Furthermore, the hypothalamus is connected with the antinociceptive system represented by the rostro ventromedial medulla oblongata, the serotonergic raphe nuclei, the noradrenergic locus coeruleus, and the periaqueductal gray (PAG) matter. The ventrolateral part of the PAG is probably the most interesting anatomical region for the connectivity of headache and sleep: it can 
cause "rapid-eye-movement sleep-off" when activated by orexin. Furthermore, orexin can stimulate neurons in the ventrolateral part of the PAG, which inhibits antinociceptive activity in the trigeminal nucleus caudalis (ie, facilitates trigeminal nociception), triggering a migraine attack. The orexinergic neurons of the posterior hypothalamus are involved both in inhibition of analgesia and in sleep disorders such as narcolepsy. ${ }^{86}$ Dysfunctional hypothalamic activity might contribute to both altered sleep-wake function and altered pain processing via its orexinergic neurons. ${ }^{87}$

It is therefore very likely that pain processing can be modulated via these circuits by vegetative/autonomic symptoms and reflex mechanisms: sleep can trigger a migraine attack (involving the posterior hypothalamus and orexinergic system), and on the other hand, through changes of the autonomic homoeostasis, it can facilitate or suppress pain processing. ${ }^{86}$

\section{Conclusion}

Clinical, anatomical, biochemical, and pathophysiologic evidence supports the association between sleep and the genesis of headache in biologically predisposed persons.

Summing up the review, we can conclude that the prevalence studies demonstrated a relationship between headache and sleep disorders based mainly on association and not on causality. Polysomnographic studies indicated a strong clinical association between migraine and sleepdisordered breathing.

On the other hand, lack of sleep or excessive sleep duration can represent a causative factor for headache, and circadian abnormalities seem to have a triggering role for headache attacks, suggesting a causality or reinforcement in subjects with headache.

This relationship is most evident for primary headache disorders and especially in childhood; in this view, sleep problems are considered as predisposing, predictive, or even prognostic factors for headache development or endurance. In children and adolescents with a predisposition to headache, any disruption of sleep or a simple alteration of the sleep-wake cycle might lead to the onset of an acute headache attack.

The hypothesized structural alteration of the neurotransmitter (serotoninergic and dopaminergic) pathways affecting migraine and sleep might be active from the early period of life, leading to disorders of the sleep-wake rhythm in infancy that tend to persist during childhood and adolescence and to the development of a comorbid headache disorder.
Therefore, the clinical evaluation of childhood headache should include a careful analysis of sleep habits and patterns and the evaluation of the presence of sleep disturbances, in order to develop better treatment methods for both sleep and headache.

\section{Disclosure}

The authors report no conflicts of interest in this work.

\section{References}

1. Hill W. On some causes of backwardness and stupidity in children: and the relief of these symptoms in some instances by naso-pharyngeal scarifications. Br Med J. 1889;2:711-712.

2. Headache Classification Subcommittee of the International Headache Society. The International Classification of Headache Disorders, 2nd ed. Cephalalgia. 2004;24 Suppl 1:9-160.

3. Alberti A. Headache and sleep. Sleep Med Rev. 2006;10:431-437.

4. Brennan KC, Charles A. Sleep and headache. Semin Neurol. 2009;29: 406-418.

5. Lovati C, D'Amico D, Raimondi E, Mariani C, Bertora P. Sleep and headache: a bidirectional relationship. Expert Rev Neurother. 2010;10: $105-117$.

6. Kelman L, Rains JC. Headache and sleep: examination of sleep patterns and complaints in a large clinical sample of migraineurs. Headache. 2005;45:904-910.

7. Bille B. Migraine in childhood and its prognosis. Cephalalgia. 1981;1: 71-75.

8. Ohayon MM. Prevalence and comorbidity of sleep disorders in general population. Rev Prat. 2007;57:1521-1528.

9. Sahota PK, Dexter JD. Sleep and headache syndromes: a clinical review. Headache. 1990;30:80-84.

10. Jennum P, Jensen R. Sleep and headache. Sleep Med Rev. 2002;6 471-479.

11. Dodick DW, Eross EJ, Parish JM, Silber M. Clinical, anatomical, and physiologic relationship between sleep and headache. Headache. 2003;43:282-289.

12. Merikangas KR. Contributions of epidemiology to our understanding of migraine. Headache. 2013;53:230-246.

13. Owens JA, Whitmans M. Sleep problems. Curr Probl Pediatr Adolesc Health Care. 2004;34:154-157.

14. Elser JM, Woody RC. Migraine headache in the infant and young child. Headache. 1990;30:366-368.

15. Nobre ME, Leal AJ, Filho PM. Investigation into sleep disturbance of patients suffering from cluster headache. Cephalalgia. 2005;25: 488-492.

16. Valrie CR, Bromberg MH, Palermo T, Schanberg LE. A systematic review of sleep in pediatric pain populations. J Dev Behav Pediatr. 2013;34:120-128.

17. Roth-Isigkeit A, Thyen U, Stöven H, Schwarzenberger J, Schmucker P. Pain among children and adolescents: restrictions in daily living and triggering factors. Pediatrics. 2005;115:e152-e162.

18. Bruni O, Fabrizi P, Ottaviano S, Cortesi F, Giannotti F, Guidetti V. Prevalence of sleep disorders in childhood and adolescence with headache: a case-control study. Cephalalgia. 1997;17:492-498.

19. Miller VA, Palermo TM, Powers SW, Scher MS, Hershey AD. Migraine headaches and sleep disturbances in children. Headache. 2003;43: 362-368.

20. Barbanti P, Aurilia C, Egeo G, Fofi L, Vanacore N. A case-control study on excessive daytime sleepiness in chronic migraine. Sleep Med. 2013;14:278-281.

21. Provini F, Vetrugno R, Lugaresi E, Montagna P. Sleep-related breathing disorders and headache. Neurol Sci. 2006; 27(S2):S149-52.

22. Rains JC, Poceta JS. Sleep-related headaches. Neurol Clin. 2012;30: 1285-1298. 
23. Seidel S, Hartl T, Weber M, et al. Quality of sleep, fatigue and daytime sleepiness in migraine - a controlled study. Cephalalgia. 2009;29: 662-669.

24. Ong JC, Stepanski EJ, Gramling SE. Pain coping strategies for tensiontype headache: possible implications for insomnia? J Clin Sleep Med. 2009;5:52-56.

25. Isik U, Ersu RH, Ay P, et al. Prevalence of headache and its association with sleep disorders in children. Pediatr Neurol. 2007;36: 146-151.

26. Esposito M, Roccella M, Parisi L. Hypersomnia in children affected by migraine without aura: a questionnaire-based case-control study. Neuropsychiatr Dis Treat. 2013;9:289-294.

27. Luc ME, Gupta A, Birnberg JM, Reddick D, Kohrman MH. Characterization of symptoms of sleep disorders in children with headache. Pediatr Neurol. 2006;34:7-12.

28. Dahmen N, Querings K, Grün B, Bierbrauer J. Increased frequency of migraine in narcoleptic patients. Neurology. 1999;52: 1291-1293.

29. Dahmen N, Kasten M, Wieczorek S, Gencik M, Epplen JT, Ullrich B. Increased frequency of migraine in narcoleptic patients: a confirmatory study. Cephalalgia. 2003;23:14-19.

30. Carotenuto M, Guidetti V, Ruju F, Galli F, Tagliente FR, Pascotto A. Headache disorders as risk factors for sleep disturbances in school aged children. J Headache Pain. 2005;6:268-270.

31. Pakalnis A, Splaingard M, Splaingard D, Kring D, Colvin A. Serotonin effects on sleep and emotional disorders in adolescent migraine. Headache. 2009;49:1486-1492.

32. Rizzo R, Conti I, Verrotti A, et al. Primary headaches in children: clinical findings on the association with other conditions. Int J Immunopathol Pharmacol. 2012;25:1083-1091.

33. Guidetti V, Galli F, Fabrizi P, et al. Headache and psychiatric comorbidity: clinical aspects and outcome in an 8-year follow-up study. Cephalalgia. 1998;18:455-462.

34. Jan MM, Al-Buhairi AR. Is infantile colic a migraine-related phenomenon? Clin Pediatr (Phila). 2000;40:295-297.

35. Katerji MA, Painter MJ. Infantile migraine presenting as colic. J Child Neurol. 1994;9:336-337.

36. Guidetti V, Ottaviano S, Pagliarini M. Childhood headache risk: warning signs and symptoms present during the first six months of life. Cephalalgia. 1984;4:237-242.

37. Del Bene E. Multiple aspects of headache risk in children. Adv Neurol. 1982;33:187-198.

38. Fox AW, Davis RL. Migraine chronobiology. Headache. 1998;38: 4364-4341.

39. Guidetti V, Bruni O, Violani C, Casiello B, Devoto A, Galli F. Sleep wake cycle variations in migrainous children. Cephalalgia. 1999;19:278.

40. Nagtegaal JE, Smits MG, Stuart ACW, Kerkhof GA, van der Meer YG. Melatonin-responsive headache in delayed sleep phase syndrome: preliminary observations. Headache. 1998;38:303-307.

41. Bruni O, Galli F, Guidetti V. Sleep hygiene and migraine in children and adolescents. Cephalalgia. 1999;25:57-59.

42. Peres MF. Melatonin, the pineal gland and their implications for headache disorders. Cephalalgia. 2005;25:403-411.

43. Claustrat B, Loisy C, Brun J, Beorchia S, Arnaud JL, Chazot G. Nocturnal plasma melatonin levels in migraine: a preliminary report. Headache. 1989;29:242-245.

44. Murialdo G, Fonzi S, Costelli P, et al. Urinary melatonin excretion throughout the ovarian cycle in menstrually related migraine. Cephalalgia. 1994;14:205-209.

45. Brun J, Claustrat B, Saddier P, Chazot G. Nocturnal melatonin excretion is decreased in patients with migraine without aura attacks associated with menses. Cephalalgia. 1995;15:136-139.

46. Peres MF, Sanchez del Rio M, Seabra ML J, et al. Hypothalamic involvement in chronic migraine. JNeurol Neurosurg Psychiatry. 2001;71: 747-751.

47. Claustrat B, Brun J, Geoffriau M, Zaidan R, Mallo C, Chazot G. Nocturnal plasma melatonin profile and melatonin kinetics during infusion in status migrainosus. Cephalalgia. 1997;17:511-517.
48. Nagtegaal JE, Laurant MW, Kerkhof GA, Smits MG, van der MeerYG, Coenen AM. Effects of melatonin on the quality of life in patients with delayed sleep phase syndrome. J Psychosom Res. 2000;48:45-50.

49. Chazot G, Claustrat B, Brun J, Jordan D, Sassolas G, Schott B. A chronobiological study of melatonin, cortisol growth hormone and prolactin secretion in cluster headache. Cephalalgia. 1984;4: 213-220.

50. Waldenlind E, Gustafsson SA, Ekbom K, Wetterberg L. Circadian secretion of cortisol and melatonin in cluster headache during active cluster periods and remission. J Neurol Neurosurg Psychiatry. 1987;50:207-213.

51. Waldenlind E, Ekbom K, Wetterberg L, et al. Lowered circannual urinary melatonin concentrations in episodic cluster headache. Cephalalgia. 1994:14:199-204.

52. Leone M, Lucini V, D'Amico D, et al. Twenty-four-hour melatonin and cortisol plasma levels in relation to timing of cluster headache. Cephalalgia. 1995;15:224-229.

53. Leone M, D'Amico D, Moschiano F, Fraschini F, Bussone G. Melatonin versus placebo in the prophylaxis of cluster headache: a double-blind pilot study with parallel groups. Cephalalgia. 1996;16:494-496.

54. Peres MF, Rozen TD. Melatonin in the preventive treatment of chronic cluster headache. Cephalalgia. 2001;21:993-995.

55. Capo G, Esposito A. Hypnic headache: a new Italian case with a good response to pizotifene and melatonin. Cephalalgia. 2001;21: 505-506.

56. Rozen TD. Melatonin as treatment for indomethacin-responsive headache syndromes. Cephalalgia. 2003;23:734-735.

57. Rozen TD. Melatonin as treatment for idiopathic stabbing headache. Neurology. 2003;61:865-866

58. Miano S, Parisi P, Pelliccia A, Luchetti A, Paolino MC, Villa MP. Melatonin to prevent migraine or tension-type headache in children. Neurol Sci. 2008;29:285-287.

59. Bursztein C, Steinberg T, Sadeh A. Sleep, sleepiness, and behavior problems in children with headache. $J$ Child Neurol. 2006;21: 1012-1019.

60. Bruni O, Russo PM, Violani C, Guidetti V. Sleep and migraine: an actigraphic study. Cephalalgia. 2004;24:134-139.

61. Dexter JD, Weitzman ED. The relationship of nocturnal headaches to sleep stage patterns. Neurology. 1970;20:513-518.

62. Russo PM, Bruni O, Lucidi F, Ferri R, Violani C. Sleep habits and circadian preference in Italian children and adolescents. $J$ Sleep Res. 2007;16:163-169.

63. Gori S, Morelli N, Maestri M, et al. Sleep quality, chronotypes and preferential timing of attacks in migraine without aura. $J$ Headache Pain. 2005;6:258-260.

64. Soriani S, Fiumana E, Manfredini R, et al. Circadian and seasonal variation of migraine attacks in children. Headache. 2006;46:1571-1574.

65. Giannotti F, Cortesi F, Sebastiani T, Ottaviano S. Circadian preference, sleep and daytime behaviour in adolescence. J Sleep Res. 2002;11: 191-199.

66. Larsson B, Myron Z. Swedish school nurses' view of school health care utilization, causes and management of recurrent headaches among school children. Scand J Caring Sci. 2003;17:232-238.

67. Bruni O, Russo PM, Ferri R, Novelli L, Galli F, Guidetti V. Relationships between headache and sleep in a non-clinical population of children and adolescents. Sleep Med. 2008;9:542-548.

68. Eidlitz-Markus T, Haimi-Cohen Y, Steier D, Zeharia A. Effectiveness of nonpharmacologic treatment for migraine in young children. Headache. 2010;50:219-223.

69. Blau JN. Resolution of migraine attacks: sleep and the recovery phase. J Neurol Neurosurg Psychiatry. 1982;45:223-226.

70. Aaltonen K, Hamalainen ML, Hoppu K. Migraine attacks and sleep in children. Cephalalgia. 2000;20:580-584.

71. Inamorato E, Minatti Hannuch SN, Zukerman E. The role of sleep in migraine attacks. Arq Neuropsiquiatr. 1993;51:429-432.

72. Gans M. Part II. Treating migraine by "sleep-rationing." J Nerv Ment Dis. 1951;113:405-429. 
73. Guidetti V, Bruni O, Canitano R, Romoli M, Napoli L. Migraine and headache in childhood: sleep disorders and sleep organization. Cephalalgia. 1995;15(S16):10-12.

74. Paiva T, Batista A, Martins P, Martins A. The relationship between headaches and sleep disturbances. Headache. 1995;35:590-596.

75. Vendrame M, Kaleyias J, Valencia I, Legido A, Kothare SV. Polysomnographic findings in children with headaches. Pediatr Neurol. 2008;39:6-11.

76. Vgontzas AN, Chrousos GP. Sleep, the hypothalamic-pituitary adrenal axis, and cytokines: multiple interactions and disturbances in sleep disorders. Endocrinol Metab Clin North Am. 2002;31:15-36.

77. Straube A, Förderreuther S. Sleeping behaviour and headache attacks in cases of primary headache. Possible pathological mechanisms. Schmerz. 2004;18:300-305. German.

78. Rains JC, Poceta SJ, Penzien DB. Sleep and headaches. Curr Neurol Neurosci Rep. 2008;8:167-175.

79. Rains JS, Poceta JC. Headache and sleep disorders: review and clinical implications for headache management. Headache. 2006;46: 1344-1361.
80. Marmura MJ. Use of dopamine antagonists in treatment of migraine. Curr Treat Options Neurol. 2012;14:27-35.

81. Peres MF, Zukerman E, da Cunha Tanuri F, Moreira FR, Cipolla-Neto J. Melatonin, $3 \mathrm{mg}$, is effective for migraine prevention. Neurology. 2004;24:757.

82. Peres MF. Melatonin for migraine prevention. Curr Pain Headache Rep. 2011;15:334-335.

83. Ong JC, Park M. Chronic headaches and insomnia: working toward a biobehavioral model. Cephalalgia. 2012;32:1059-1070.

84. Mascia A, Afra J, Schoenen J. Dopamine and migraine: a review of pharmaceutical, biochemical, neurophysiological and therapeutic data. Cephalalgia.1998;18:174-182.

85. Annequin D, Dumas C, Tourniaire B, Massiou H. Migraine and chronic headache in children. Rev Neurol (Paris). 2000;156 Suppl 4: 4S68-64S74. French.

86. Evers S. Sleep and headache: the biological basis. Headache. 2010;50: 1246-1251.

87. Holland PR. Modulation of trigeminovascular processing: novel insights into primary headaches. Cephalalgia. 2009;29 Suppl 3:1-6.
Nature and Science of Sleep

\section{Publish your work in this journal}

Nature and Science of Sleep is an international, peer-reviewed, open access journal covering all aspects of sleep science and sleep medicine, including the neurophysiology and functions of sleep, the genetics of sleep, sleep and society, biological rhythms, dreaming, sleep disorders and therapy, and strategies to optimize healthy sleep. The journal welcomes

\section{Dovepress}

original research, clinical \& epidemiological studies, reviews \& evaluations, case reports and extended reports. The manuscript management system is completely online and includes a very quick and fair peerreview system, which is all easy to use. Visit http://www.dovepress.com/ testimonials.php to read real quotes from published authors. 